\title{
A Review of Techniques for Visualising Soft Tissue Microstructure Deformation and Quantifying Strain Ex Vivo
}

\author{
C.M. Disney ${ }^{1,2 *}$, P.D. Lee ${ }^{3}$, J.A. Hoyland ${ }^{2,4}$, M.J. Sherratt ${ }^{2}$, B.K. Bay ${ }^{5}$ \\ ${ }^{1}$ Centre for Doctoral Training in Regenerative Medicine, ${ }^{2}$ Division of Cell Matrix Biology \\ and Regenerative Medicine, ${ }^{3}$ School of Materials, University of Manchester, UK.
}

${ }^{4}$ NIHR Manchester Biomedical Research Centre, Central Manchester University Hospitals NHS Foundation Trust, Manchester Academic Health Science Centre, UK.

${ }^{5}$ School of Mechanical, Industrial and Manufacturing Engineering, Oregon State University, Corvallis, OR, US.

Author email addresses: C.M. Disney (catherine.disney@postgrad.manchester.ac.uk), P.D. Lee (peter.lee@manchester.ac.uk), J.A. Hoyland (judith.a.hoyland@manchester.ac.uk), M.J. Sherratt (michael.j.sherratt@manchester.ac.uk), B.K. Bay (brian.bay@oregonstate.edu).

* Corresponding author

Correspondence to Catherine Disney (catherine.disney@postgrad.manchester.ac.uk)

Tel (+44) 1612751439

Postal address: 1.556 Stopford Building, Oxford Road, Manchester, M13 9PT. 


\begin{abstract}
Many biological tissues have a complex hierarchical structure allowing them to function under demanding physiological loading conditions. Structural changes caused by ageing or disease can lead to loss of mechanical function. Therefore, it is necessary to characterise tissue structure to understand normal tissue function and the progression of disease. Ideally intact native tissues should be imaged in 3D and under physiological loading conditions. The current published in situ imaging methodologies demonstrate a compromise between imaging limitations and maintaining the samples native mechanical function. This review gives an overview of in situ imaging techniques used to visualise microstructural deformation of soft tissue, including three case studies of different tissues (tendon, intervertebral disc and artery). Some of the imaging techniques restricted analysis to observational mechanics or discrete strain measurement from invasive markers. Full-field local surface strain measurement has been achieved using digital image correlation. Volumetric strain fields have successfully been quantified from in situ X-ray micro tomography (microCT) studies of bone using digital volume correlation but not in soft tissue due to low X-ray transmission contrast. With the latest developments in microCT showing in-line phase contrast capability to resolve native soft tissue microstructure, there is potential for future soft tissue mechanics research where 3D local strain can be quantified. These methods will provide information on the local 3D micro-mechanical environment experienced by cells in healthy, aged and diseased tissues. It is hoped that future applications of in situ imaging techniques will impact positively on the design and testing of potential tissue replacements or regenerative therapies.
\end{abstract}

Keywords: MicroCT, in situ imaging, digital volume correlation (DVC), tendon, intervertebral disc (IVD), artery. 


\section{Introduction}

The mechanical function of biological tissues relies on their hierarchical structure. To fully understand normal tissue function and the progression of disease, it is necessary to visualise structure and characterise mechanical behaviour at multiple levels of tissue hierarchy and in three dimensions. Three-dimensional tissue architecture does not conveniently simplify into the two-dimensional representation given by histology. Many tissues have evolved complex structures in order to function under demanding dynamic physiological loading conditions. For example, blood vessels must accommodate to changes in pressure, tendons are required to transmit forces during movement and intervertebral discs (IVD) allow small movements between the vertebrae for the spine to bend and twist whilst supporting body weight (Figure 1). The physical and mechanical properties of these tissues are directly related to the complex and sophisticated structures created by their constituent cells and extracellular matrices (ECM). Elastic arteries have a layered structure which provides remarkable resilience and strength (Wagenseil \& Mecham, 2009). The lamellar elastin-rich medial layer protects smaller blood vessels by dampening large changes in pressure. Energy is stored during high pressure (systole) and released as the vessel returns to resting diameter (diastole). The outer collagen-rich adventitia layer restricts extreme arterial diameter changes. Fibrous connective tissue such as tendon and IVD must have low stiffness for flexibility but high strength under increasing load to bear or transmit load. This non-linear mechanical behaviour is created by a composite and hierarchical structure of aligned collagen fibrils, fibres, fibre bundles and fascicles or lamellae for tendon and IVD (Dobrynin \& Carrillo, 2010, Lake et al., 2009, Guerin \& Elliott, 2007, Storm et al., 2005).

The structure and therefore function of tissues does not however remain static. Both ageing and many associated pathologies negatively impact on tissues. The proportion of older people (aged 60 years or older) in Europe and North America is increasing and is expected to 
reach up to $21 \%$ by 2050 (United Nations, 2013). Mortality, morbidity and quality of life during old age are increasingly determined by age-related disease (Salomon et al., 2013). This can be associated with structural and mechanical changes of soft tissues such as arteriosclerosis of blood vessels (Adnan et al., 2017, Hayashi \& Hirayama, 2017, Wijesinghe et al., 2017, Sherratt, 2013, Graham et al., 2011), compositional changes in tendon (Ackerman et al., 2017, Fessel et al., 2014, Couppe et al., 2009, Goh et al., 2008) and IVD degeneration (Gullbrand et al., 2016, Richardson et al., 2014, Wang et al., 2014, Adams \& Dolan, 2012, Raj, 2008, Urban \& Roberts, 2003). Thus, the ageing population presents a major challenge for healthy ageing and medicine.

In order to understand the structure and function of healthy, aged and diseased tissues, it is necessary to characterise soft tissue microstructure under different loading conditions (Figure 1) (Fang \& Lake, 2017, Locke et al., 2017, Wan et al., 2010,). Ultrasound, MRI or CT have been used for in vivo mechanics studies allowing accurate physiological loading (Franz et al., 2015, Yoder et al., 2014, Martin et al., 2013). However, these techniques have limited resolution and are unable to resolve microstructure which is central to native tissue mechanical function and cell-matrix interactions (Screen et al., 2015, Neidlinger-Wilke et al., 2014, Setton \& Chen, 2006). Therefore, this review only includes microstructural imaging of ex vivo samples. Experimental mechanics and imaging studies of ex vivo samples have the potential to recapitulate soft tissue microstructure and function required for the development and testing of novel tissue engineering or regenerative therapies (Appel et al., 2013, Pedersen \& Swartz, 2005). Here we review in situ imaging techniques - a combination of mechanical loading and imaging - used to visualise soft tissue microstructure under load and to quantify or map strain. Focus is on the compromise between optimal imaging characteristics and maintaining native mechanical function.

\section{Imaging soft tissue microstructure to observe mechanical function}




\subsection{Imaging soft tissue microstructure}

Optical microscopy techniques are commonly used to identify constituent cells and ECM in tissue. Histological visualisation requires micro-spatial resolution and sufficient contrast between cells and ECM structural components. Image contrast between different structures and compositional information can be determined by their affinity for various stains.

Although serial sectioning and reconstruction can be employed to visualise structures in $3 \mathrm{D}$, the approach is labour intensive and has varied results (Mizutani \& Suzuki, 2012).

Problematic sections may have to be discarded for a low error reconstruction. Moreover when viewed by these sectioning techniques, their structure may not be representative as in their natural environment. Sectioning often results in structural damage artefacts such as tears, fractures, folds and compressions. Ideally imaging should be 3D and non-destructive, leaving the tissue intact in its physiological environment (Walton et al., 2015).

Optical coherence tomography (OCT) uses a relatively longer wavelength light than standard histology and so is capable of penetrating deeper into the tissue (1-2 $\mathrm{mm})$ allowing imaging of mesoscale volumes. Optical clearing of specimens can help to reduce light scattering and hence improve imaging depth. Richardson and Lichtman (2015) review various clearing techniques showing that protocols can range from hours to months and importantly clearing causes changes in tissue morphology. The 3D structural complexity of tissues can be imaged using OCT, for example the connectivity of translamellar cross bridges in the IVD (Han et al., 2015). Furthermore, OCT uses intact native samples allowing for imaging during functional conditions such as artery stiffness changes in pressurised diseased arteries (Adnan et al., 2017). Confocal microscopy has higher resolution than OCT but imaging thickness is limited to a few hundred microns and is only capable of viewing in-plane or nearly in-plane features. The higher resolution, achieved by a focussed high intensity beam and a pinhole to select in focus regions, allows visualisation of microstructures which are responsible for soft 
tissue mechanical behaviour (Wang et al., 2013, Michalek et al., 2009, Bruehlmann et al., 2004).

$\mathrm{X}$-ray micro tomography (microCT) is capable of 3D imaging of relatively large intact specimens at micro-spatial resolution. In comparison to the above imaging techniques, X-rays are more transmissive and less refractile. This means that they can penetrate the specimen with the ability for non-destructive 3D imaging. Two observations can be made once X-ray radiation has passed through a sample; i) the wave's amplitude is reduced due to absorption (dependent on the electron density of the sample) ii) the wave front is distorted (phase distortion) due to the wave travelling at different speeds through different areas of attenuation in the sample. Transmission based X-ray tomography records a cross-section of the sample according to the intensity of the X-rays after passing through the sample. The sample is mounted and rotated by a stage to gather many projections which are reconstructed to form a 3D image. The first cone beam reconstruction algorithm (Feldkamp et al., 1984) enabled 3D histological resolution imaging of cancellous bone (Feldkamp et al., 1989). Contrast in these samples is due to the high-atomic-number of the mineralised constituent (calcium phosphate).

Conversely soft tissue is composed of low-atomic-number elements (carbon, hydrogen, oxygen) and so has low X-ray transmission contrast. The comparable level of hydration within the different components of soft tissue also contributes to low absorption contrast and lack of resolved detail. Contrast enhancement can be achieved using heavy element staining agents or by drying the sample, both of which cause distortion and changes in material properties. Simple drying of soft tissue leads to shrinkage and significant damage to the tissue's native structure. Freeze drying and critical point drying reduce but do not eliminate these artefacts (Zysk et al., 2012, Happel et al., 2010). The use of contrast agents is less complicated than drying procedures as they do not require any special conditions such as controlled temperature and pressure. Staining affinity and protocols are not well defined but 
this is a growing field with a number of recent publications in whole model organisms and organs to distinguish gross anatomy (Helfenstein-Didier et al., 2017, Descamps et al., 2014, Pauwels et al., 2013, Mizutani \& Suzuki, 2012, Metscher, 2009a, Metscher, 2009b) and at tissue level to resolve the microstructure of collagenous tissues and vasculature (Figure 2a) (Disney et al., 2017, Balint et al., 2016, Shearer et al., 2016, Nieminen et al., 2015, Nierenberger et al., 2015). A degree of tissue preservation or fixation is required for staining (mostly ethanol based) which alters tissue structure and mechanics (Tilley et al., 2011, Hickey \& Hukins, 1979). Long staining times are often required for diffusion of contrast agents into bulk tissue samples, and this has been shown to cause tissue distortion (Disney et al., 2017, Balint et al., 2016, Vickerton et al., 2013).

It is possible to resolve soft tissue microstructure without the use of stains using in-line phase contrast enhancement (Disney et al., 2017, Walton et al., 2015, Naveh et al., 2014, Jiang et al., 2012, Kalson et al., 2012). This method proposed in the 90s (Wilkins et al., 1996, Snigirev et al., 1995) requires a partially coherent source but does not require any additional optics. The detector is moved away from the sample to provide sufficient propagation for Fresnel diffraction to occur from the wave front distortion. The interference Fresnel fringes increase structure edge resolution. In-line phase contrast enhancement has been used with both synchrotron and laboratory microfocus sources. Walton et al. (2015) used phase contrast enhanced microCT to visualise microstructural changes in pressurised embedded arteries. Their high resolution scans are able to resolve structural remodelling such as an increase in lumen cross-sectional area, straightening of the medial elastic lamellae and remodelling in the adventitial layer (Figure 2b). However, this methodology is limited to an observational study as the tissue was chemically fixed and paraffin embedded and so a direct comparison cannot be made before and after pressurisation of the same artery. It is difficult to conduct in situ experiments with laboratory phase contrast methods, as creating coherence reduces X-ray 
flux considerably and scan time become very long (days). The success and challenges of in situ imaging for soft tissue mechanics measurement are described in the next two sections and summarised in Figure 3.

\subsection{In situ imaging to observe microstructural deformation mechanisms}

Microstructural deformation mechanisms and local strain attenuation is important for native tissue mechanical function. Mechanisms such as collagen fibre sliding, fibre uncrimping, fibre realignment and attenuation by structural heterogeneities have been observed in connective tissue imaging studies. Three case studies of soft tissue in situ imaging studies are given below.

\subsubsection{Tendon}

Tendon is a strong fibrous collagen tissue with a hierarchical structure of fibrils, fibres and fascicles (Figure 4a), whose mechanical role is to transmit forces between muscle and bone. The reader can find detailed information on tendon mechanics in a recently published review (Fang \& Lake, 2017). Initially tendon fibres uncrimp and realign but the major deformation mechanism is fibre or fascicle sliding under load and during relaxation (Fang \& Lake, 2015, Thorpe et al., 2015, Szczesny \& Elliott, 2014, Gupta et al., 2010, Screen et al., 2004). This sliding mechanism indicates load is transferred through the tissue by shear as the fibres do not bear load independently (Szczesny \& Elliott, 2014). Confocal microscopy has frequently been used where cell nuclei are stained and tissue mechanics inferred by cell movement (Gupta et al., 2010, Screen et al., 2004). Photobleached lines have also been used to visually observe tissue mechanics (Fang \& Lake, 2015, Szczesny \& Elliott, 2014) but the DTAF stain used has been shown to alter tissue mechanics (Szczesny et al., 2014). 
The main challenge in tendon mechanics research is that their shape and loading conditions are extremely varied. The deformation mechanisms depend on loading conditions: for example, shear attenuation is dominated by fibre sliding whereas compression attenuation is dominated by uncrimping and fibre reorganisation in the rotator cuff tendon (Fang \& Lake, 2015). To accurately observe and measure microstructure deformation further studies are required using different loading conditions and 3D imaging.

Whilst fascicle sliding is clearly a major microstructural deformation mechanism, the contribution of sliding is dependent on the tendon type (energy storing versus force transmission) and governed by tendon composition, specifically the interfascicular matrix characteristics (Thorpe et al., 2015). Similarly differing composition of fibrocartilage (proteoglycan micro-domains) has been shown to influence overall deformation and the subtle local heterogeneities responsible for the complex deformation mechanisms (Han et al., 2016). To fully understand this behaviour between tendon types a full-field local strain map is required.

\subsubsection{Intervertebral disc}

Intervertebral discs are located between the vertebrae in the spine where they provide flexibility whilst bearing load from body weight and physical activity (Newell et al., 2017, Adams et al., 1996, Panjabi et al., 1994). At the centre of the disc there is an amorphous gellike core (nucleus pulposus), composed of the proteoglycan aggrecan and type II collagen (Taylor et al., 1992), surrounded by a ring of fibrocartilage (annulus fibrosus) which has residual strain in the unloaded state (Figure 4b)(Michalek et al., 2012). The annulus fibrosus (AF) is composed of concentric lamellae with alternating angled collagen I fibril bundles (Marchand \& Ahmed, 1990, Cassidy et al., 1989, Humzah \& Soames, 1988, Eyre \& Muir, 1977). This highly organised and multi-scale structure is responsible for the tissue's anisotropic mechanical behaviour. Sections of AF from the IVD have been imaged under 
load using confocal techniques. Collagen fibrils uncrimped or stretched whilst bundles reoriented and were observed sliding past each other (Vergari et al., 2016, Michalek et al., 2009, Bruehlmann et al., 2004). There's some inconsistency in the observations made at the lamellae boundaries. Bruehlmann et al. (2004) reported cells undergo large motions in the interlamellar space suggesting slipping between lamellae. Whereas Michalek et al. (2009) and Vergari et al. (2016) described no slipping at lamella boundaries. These studies used a 2D imaging technique and different loading conditions of dissected samples for an anisotropic tissue. Cutting samples from the intact structure relieves and disrupts the residual stress state and consequently changing the response to applied loads. The problem is particularly acute with non-linear materials which shift into different stiffness regimes with the release of residual stress. Further research is required to study IVD microstructural deformation mechanisms in intact samples.

\subsubsection{Vascular}

Arteries carry blood away from the heart and so are required to withstand cyclic changes in pressure. Composed of three concentric layers; collagen fibres make up a connective tissue (tunica adventitia) which surrounds the outside of the vessel, smooth muscle cells and elastic tissue form the central layer (tunica media) and endothelia cells line the inside (tunic intima) (Figure 4c). A reduction of waviness in the elastic lamellae of arteries has been seen with increased internal pressure using confocal and electron microscopy (Krasny et al., 2017, Schrauwen et al., 2012, O'Connell et al., 2008, Wolinsky \& Glagov, 1964) and more recently using microCT (Walton et al., 2015). In pioneering studies, unfixed arterial tissue was loaded in situ, imaged using confocal techniques and uncrimping of collagen fibres was consistently observed (Cavinato et al., 2017, Krasny et al., 2017, Schrauwen et al., 2012). However, there are differing observations regarding the realignment of fibres which may be related to the diverse sample dissection and loading conditions. Cavinato et al. (2017) used bulge inflation 
on segments of tissue (not an intact vessel) and aimed to mimic in vivo luminal pressures. Schrauwen et al. (2012) used whole-body inflation tests over a range of pressures some of which were not physiological. Krasny et al. (2017) applied uniaxial loading in three directions to rectangular strips of tissue. Cavinato et al. (2017) states that there was not evident reorientation of collagen fibres under pressurisation, whereas Schrauwen et al. (2012) describes fibres aligning to form a symmetrical double helix and Krasny et al. (2017) observes realignment of fibres in the applied loading direction. Whilst each study is valuable in characterising structure and mechanical function of arterial tissue, these studies highlight the importance of careful sample preparation and choice of loading mode. The experimental design and conclusions therefore must be interpreted with caution.

The above case studies show how sample preparation required for imaging and choice of loading can affect experimental outcome. Dissecting samples can lead to release of residual strain, and since soft tissue are viscoelastic, this changes their mechanical response to applied loads. Therefore, the desired imaging technique should leave the tissue intact. Furthermore, 2D confocal imaging techniques do not fully capture tissue deformation of an intact sample and so 3D imaging is required. Full-field strain measurement could prove important to investigate deformation mechanisms and how variations in tissue composition, such as proteoglycan content, influence overall and local deformation behaviour.

\section{Tracking microstructure to map local strain}

\subsection{Discrete strain measurement}

Tissue strain has been measured by tracking discrete markers (Fang \& Lake, 2015, Karakolis \& Callaghan, 2015), beads (Lake et al., 2009), wires or tissue stained with regularly ordered patterns (Fang \& Lake, 2015, Szczesny \& Elliott, 2014). Tracking discrete markers or patterns provides information on the tissue global biomechanical response. However, these 
methods are invasive, causing disruption to native structure, and the strain field is inferred from isolated points. The local biomechanical response can be tracked by digital image correlation (DIC) to calculate full-field strain.

\subsection{Full-field strain measurement}

\subsubsection{Digital image correlation}

Applied speckle patterns or the sample's native structure can be tracked using 2D digital image correlation (DIC) to provide displacement fields (Bay, 1995, Sutton et al., 1986, Sutton et al., 1983). Table 1 gives examples of soft tissue studies which have used DIC to map strain. Distinct surface features are required for DIC and so frequently a highly-contrasted speckle pattern is created on the sample using stains and ink (Lionello et al., 2014). Briefly, the sample is imaged in its undeformed (reference image) and deformed state and surface patterns correlated for many (often thousands) of subsets distributed over a region of interest. Each subset is tracked from the reference image into the deformed state by optimization of a normalized cross-correlation or sum of squared difference function. Change in location of subsets yields displacements, from which gradients are calculated and organised into a fullfield surface strain tensor representation. A variety of cameras and microscopes are used as sources of digital images for correlation studies, with the proper imaging method depending on sample size, loading rates, and other considerations. DIC is a well-developed methodology in many areas of experimental mechanics, but soft tissue studies present unique difficulties. Applying speckle patterns to uneven and wet surfaces can be troublesome and cause imaging artefacts such as shadows or reflections. Polarized light can be used to reduce reflections and scattering from wet tissue (LePage et al., 2016). In most cases it is not possible to correlate image areas close to object edges. Locke et al. (2017) used DIC to map surface strain of a damaged rotator cuff tendon. But, they were not able to correlate the images close to the defect site (edge) and their study used 2D imaging which is limited to planar samples. If the 
sample deforms out-of-plane, then in-plane displacement and strain measurements become unreliable with 2D single camera DIC. It is possible to resolve and track non-planar surfaces using stereo imaging and 3D DIC (Mallett \& Arruda, 2017, Baldit et al., 2014, Lionello et al., 2014, Badel et al., 2012, Kim et al., 2012, Ning et al., 2010, Sutton et al., 2008).

Additionally, panoramic digital image correlation p-DIC has more recently been developed for full surface strain field of arteries (Bersi et al., 2016, Genovese et al., 2013, Genovese, 2009).

CCD cameras have been used to study the surface deformation of tendon (Locke et al., 2017), ligament (Mallett \& Arruda, 2017, Lionello et al., 2014), blood vessels (Kim et al., 2012) and IVD tissue (Baldit et al., 2014). In these studies, cameras were capable of tracking speckle patterns to map tissue-scale strain distributions but failed to resolve sufficient native tissue structure for tracking. Higher resolution microscopy techniques are able to use tissue structure to track deformation. For example, the displacement of stained cell nuclei was tracked in a murine carotid artery using a stereomicroscope and 3D DIC (Badel et al., 2012, Ning et al., 2010, Sutton et al., 2008). Similarly, chondrocytes in cartilage were imaged using confocal microscopy which provided sufficient texture to map strain (Kaviani et al., 2016, Amini et al., 2013). Second harmonic generation (SHG) confocal microscopy can resolve collagenous structures without the use of stains. The natural texture of the collagen bundles imaged using SHG has been used to map strain in IVD annulus fibrosus tissue (Vergari et al., 2017, Vergari et al., 2016). Vergari et al. (2016) were able to relate the local strain measurements to the microstructure of the tissue, showing low strain at the lamellae boundaries and higher strain or shear depending on the orientation of collagen bundles and loading direction. The main weakness of this method is that the tissue had to be dissected and loaded which impacts on the physiological relevance and strain analysis. Firstly, physiological and consistent loading is difficult to achieve on a dissected section of tissue 
which has anisotropic mechanical properties. Many biological tissues have a residual strain which is released once dissected (Michalek et al., 2012). Secondly, it was only possible to analyse strain in 2D and so their data must be approached with caution as out-of-plane deformation cannot be accounted for. Finally, there should be careful definition and interpretation of strain from 2D imaging. Local strain mapping using DIC may lead to different conclusions than strain measurement from discrete points. For example, low strain at the lamella boundary measured using DIC but high inter-lamella strain from discrete measurement. The author's conclusion that these strain measurements may be related to lamellae skewing would be more convincing if 3D imaging and analysis were used.

\subsubsection{Digital volume correlation}

Digital volume correlation (DVC) aims to overcome some of the limitations of both 2D and 3D DIC methods. DVC utilises volumetric imaging modalities, most commonly but not exclusively X-ray tomography, as the basis of tracking. A volumetric region of interest is populated with small sub-volumes, which are then tracked between the reference and deformed image data sets gathered during in situ experimentation. Tracking methodology and data analysis are similar in principle to DIC, but the result is not limited to a sample surface, extending instead throughout the interior.

The first application of DVC was continuum-level strain mapping in trabecular bone from laboratory microCT data (Bay et al., 1999). It was successful due to the readily resolved open cellular structure, creating distinct local texture similar to the applied speckle patterns used in DIC. Global approaches have recently emerged as an adjunct to the more common local approaches, with constraints on displacements introduced to help control tracking uncertainty (Roux et al., 2008). 
Since the first application of DVC, strain has been mapped in different bone types and scaffold implants. To approach tissue-level strains, high resolution scans using synchrotron radiation should be taken to resolve textural details within the bone (Dall'Ara et al., 2017). These studies have demonstrated the importance of ensuring that appropriate local texture is available for reliable sub-volume tracking, and tuning DVC parameters to image texture. Authors have placed emphasis on sub-volume or subset size as a key parameter for tracking displacement uncertainties. Displacement precision improved for larger sub-volume sizes but with a trade-off in tracking resolution (Dall'Ara et al., 2017, Palanca et al., 2017, Madi et al., 2013).

OCT elastography is able to resolve soft tissue structures as small as a few micrometres and map strain in intact samples as a variant of DIC speckle (naturally occurring coherent speckle from OCT) tracking (Schmitt, 1998). The main limitation is the shallow imaging depth of around $1 \mathrm{~mm}$ which competes with resolution. The applied strain is also limited to $1-2 \%$ with higher resolution imaging (Larin \& Sampson, 2017). This is an emerging field with few studies in biological tissues such as breast tumours (Allen et al., 2016, Kennedy et al., 2015, Kennedy et al., 2014) and cornea (Lamouche et al., 2012) and two publications using DVC for 3D OCT strain measurement (Fu et al., 2013, Nahas et al., 2013).

\section{Outlook: volumetric strain measurement in soft tissue}

This review has given a brief introduction to in situ imaging and strain measurement of soft tissue. The challenges from the reviewed literature of strain measurement in soft tissue are summarised below and some suggested approaches given.

\subsection{Sample preparation and loading conditions}

\subsubsection{Precise and consistent sample dissection}


Biological tissues have complex, viscoelastic, anisotropic mechanical behaviour and therefore precise and consistent sample preparation is required. For example, two sample orientations to account for annulus fibrosus anisotropic mechanical behaviour (Michalek et al., 2009) and consistent dissection from the same anatomical region in tendon where variations in interfascicular matrix or proteoglycan content affects tissue mechanics (Han et al., 2016, Thorpe et al., 2015).

\subsubsection{Effect of sample preparation on tissue mechanics}

Consistent dissection and mechanical testing of tissues under different controlled conditions, such as uniaxial loading of the sample in multiple orientations, gives valuable material characterisation. However, dissected samples do not retain their residual strain and so intact samples should ideally be used for testing organs or tissue under physiological loads. Applying loads to dissected tissue is also challenging and may alter tissue mechanics. The vascular case study is a good illustration of differing microstructural deformation which may be as a result of the glued loading boundary of a segment of tissue compared with whole body inflation. Additionally, tissues have a natural composition gradient and irregular shape at loading interfaces which is challenging to replicate when loading dissected segments of tissue. For instance, the concave morphology of intervertebral disc endplates which varies between adjacent endplates and depends on lumbar region (Wang et al., 2012). Or a further example of composition gradient at the tendon to bone interface (Thomopoulos et al., 2003).

\subsubsection{Physiologically relevant loading regimes are limited by imaging capabilities}

Soft tissues function in a dynamic environment where loading frequency can be seconds. Observing structural deformation at this loading frequency is only possible when using imaging techniques with a short acquisition time $(<\mathrm{ms})$. Deciding on a loading protocol becomes more challenging when there are long acquisition times for $3 \mathrm{D}$ imaging techniques 
such as microCT (minutes to hours) and a long relaxation period for tissue creep. Loading must be interrupted to allow for long imaging acquisition. It is recommended all regimes follow the same general protocol below. The applied deformation step must be small enough to track using image correlation and many steps may be required depending on stiffness or physiological range. Importantly, there must be a relaxation period after each load step is applied which allows for tissue creep before image acquisition to avoid imaging artefacts.

\subsection{Imaging microstructure; towards $3 D$ imaging of native samples using microCT}

\subsubsection{Balancing contrast, resolution and field of view}

To this date in situ imaging studies are 2D or have been limited to small volumes. MicroCT has the potential to provide 3D microstructural imaging of intact native samples. Nevertheless, soft tissues are weak X-ray absorbing and so contrast enhancement is required. Contrast agents can alter tissue structure and mechanics due to long staining times and tissue preservation or fixation (Disney et al., 2017, Balint et al., 2016, Vickerton et al., 2013, Tilley et al., 2011, Hickey \& Hukins, 1979). Contrast enhancement can be achieved in native tissue using in-line phase contrast imaging techniques (Figure 2c) (Disney et al., 2017). However, laboratory microCT phase contrast approaches do not provide a large enough field of view to image the whole small animal organs at the required resolution. Synchrotron imaging has a larger field of view and has been shown to give lower tracking uncertainties for image correlation when compared to laboratory microCT (Dall'Ara et al., 2017). The considerably bright synchrotron X-rays are able to obtain higher signal:noise reconstructions and shorter scans times. A short scan time is required to mitigate against slow tissue relaxation. The high coherence and tomography beamline configurations (such as Diamond-Manchester I13-2) allow for large propagation distances which is ideal for in-line phase contrast imaging of soft tissue. 


\subsubsection{Compromise between image quality and radiation dose}

Although synchrotron microCT is capable of high signal:noise reconstructions, a balance must be made between radiation dose and scanning parameters (beam filters, number of projections and exposure time). It is recommended that the sample should be aligned in the beam under low dose conditions by using large undulator gap and shutters.

\subsubsection{Data handling and image processing}

After reconstruction it may be advantageous to process the tomography data such as using filters to reduce random noise or image artefacts. Synchrotron microCT produces large data sets which can be challenging to handle and computationally expensive to analyse. A volume of interest or some segmentation of the data to only include certain features may be required before image correlation analysis.

\subsection{Tracking displacement of features using image correlation}

\subsubsection{Sufficient features to track}

Image correlation is only possible if there are small features to track. Applied speckle patterns and image correlation have been used for mapping strain on surfaces of biological tissues. DIC measurements are sensitive to the quality of the pattern and creating a speckle pattern can be problematic for hydrated soft tissues without changes in mechanical properties. However, these methods do not provide information on internal strains and how they relate to the 3D microstructure of the tissue. DVC can be used for non-invasive sub-voxel displacement tracking using natural image texture.

\subsubsection{Tracking reliability depends on correlation parameters}

Using the DVC results it is possible to obtain a local strain map and relate it to the microstructure of the tissue. The DVC parameters must be carefully tuned to the image 
texture and aligned with the research question. It has already been shown that the sub-volume size is important for tracking uncertainty. The density and location of the tracking points may improve reliability or follow microstructures that are of interest e.g. fascicles in tendon, lamellae in IVD or collagen fibres in arterial tissue. Tuning DVC parameters will particularly be important for future in situ studies where the structures are heterogeneous and hierarchical. The influence of texture characteristics on the precision and spatial resolution of image correlation, and optimal tracking procedures for challenging conditions, are topics of continuing research. In the absence of definitive guidelines, the best strategies for ensuring reliable results are correlation of multiple image volumes under static conditions (repeat unloads), and careful analysis of residuals associated with normalised correlation functions.

\subsubsection{Correlation is inclusive of image noise and artefacts}

Image correlation is sensitive to all features in the data including noise and artefacts which can cause complications. Firstly, the level of noise may change between and within images which leads to varied reliability. Image filtering to reduce noise can help but also be detrimental if small scale features are lost. Secondly, results may appear to be reliable with excellent correlation, but displacement values are associated with motion artefacts and not to tissue deformation. Rigid body motion artefacts, once identified, can be removed by adjusting reference points for displacement values without altering relative deformations. And as proper strain measures are insensitive to rigid body motion, the calculation of strain from displacements will reveal sample deformation more definitively.

\subsection{Strain calculation and interpretation}

Strain calculation and interpretation must be appropriate for the specific tissue. For example, published work has shown collagen fibre sliding to be the main deformation mechanism in tendon and IVD and so a shear strain map may be the most appropriate measurement. 
Furthermore, choosing how to measure strain may depend on the loading mode e.g. measuring circumferential/ hoop strain for inflated arteries or in the AF of compressed IVD. Soft tissues also exhibit large, nonlinear strains, and an appropriate finite strain measure should be used, with Green-Lagrange a common choice. When interpreting results and comparing between studies it is important to take note of sample preparation, loading conditions and their strain definition for the reasons mentioned above.

\section{Conclusion}

The reviewed in situ imaging studies have been 2D or small segments of tissue. Novel application of phase contrast microCT and DVC to measure volumetric strain in native soft tissue has the potential to provide a detailed insight into tissue structural micromechanics. A proposed workflow for soft tissue microCT-DVC studies is given in Figure 5. This has the potential to bridge the gap between direct measurement of macro-mechanics and the local 3D micro-mechanical environment experienced by cells. In the long term, mechanobiology studies of soft tissues could be possible where the local strain field is related to cell mediated responses to mechanical stimuli. These studies would help characterise pathology in ageing or diseased tissues such as mechanical changes due to microstructural damage accumulation in the AF or strain patterns that develop during aortic aneurysm. Importantly these methods could be applied to accelerate development and testing of new tissue engineered replacements. 


\section{Acknowledgments}

CMD was supported by an EPSRC \& MRC Centre for Doctoral Training (CDT)

Regenerative Medicine (EP/L014904/1) studentship. PDL and BKB and the imaging was funded in part by the EPSRC-UK under grant EP/I02249X/1 at the Research Complex at Harwell. We also thank Diamond Light Source for beam time at I13-2 under proposal 12776.

These funding bodies were not involved in the writing of the manuscript, or the decision to submit the manuscript for publication. 
Table 1. Soft tissue DIC studies for mapping surface strain. Studies are organised by sample into tissue groups. Imaging and DIC method are given as well as further information about the features used for correlation (applied speckle or natural image texture)

\begin{tabular}{|c|c|c|c|c|}
\hline Study & Tissue & Origin & Imaging method & DIC method \\
\hline Locke et al., 2017 & $\begin{array}{l}\text { Rotator cuff } \\
\text { tendon-bone } \\
\text { attachment }\end{array}$ & Murine & $\begin{array}{l}\text { Optical high speed } \\
\text { camera }\end{array}$ & $\begin{array}{l}\text { Vic-2D, Correlated } \\
\text { solutions } \\
\text { Speckle pattern }\end{array}$ \\
\hline $\begin{array}{l}\text { Mallett \& Arruda, } \\
2017\end{array}$ & $\begin{array}{l}\text { Anterior cruciate } \\
\text { ligament }\end{array}$ & Ovine & $\begin{array}{l}\text { Optical high speed } \\
\text { cameras }-2 \text { FastCam, } 1 \\
\text { CCD }\end{array}$ & $\begin{array}{l}\text { Vic-3D, Correlated } \\
\text { solutions } \\
\text { Speckle ink pattern }\end{array}$ \\
\hline Lionello et al., 2014 & $\begin{array}{l}\text { Collatoral } \\
\text { ligament }\end{array}$ & Porcine & $\begin{array}{l}\text { Stereo cameras, Aramis } \\
5 \mathrm{M}\end{array}$ & $\begin{array}{l}\text { Aramis 3D DIC } \\
\text { Speckle pattern }\end{array}$ \\
\hline $\begin{array}{l}\text { Bersi et al., } 2016 \\
\text { Genovese et al., } 2013\end{array}$ & Aorta & Murine & $\begin{array}{l}\text { Optical camera } \\
45^{\circ} \text { concave conical } \\
\text { mirror }\end{array}$ & $\begin{array}{l}\text { p-DIC, MATLAB } \\
\text { (Genovese, 2009) } \\
\text { Speckle Pattern }\end{array}$ \\
\hline Wang et al., 2013 & Carotid artery & $\begin{array}{l}\text { Non- } \\
\text { human } \\
\text { primate }\end{array}$ & $\begin{array}{l}\text { Two-photon confocal } \\
\text { microscopy }\end{array}$ & $\begin{array}{l}\text { Modified OpenPIV } \\
\text { (Taylor et al., 2010) } \\
\text { Collagen fibre texture }\end{array}$ \\
\hline Kim et al., 2012 & Aorta & Human & Stereo CCD camera & $\begin{array}{l}\text { Aramis 3D DIC } \\
\text { Speckle pattern }\end{array}$ \\
\hline $\begin{array}{l}\text { Badel et al., } 2012 \\
\text { Ning et al., } 2010 \\
\text { Sutton et al., } 2008\end{array}$ & Carotid artery & Murine & Stereomicroscope & $\begin{array}{l}\text { Vic-3D, Correlated } \\
\text { solutions } \\
\text { Nuclear staining }\end{array}$ \\
\hline $\begin{array}{l}\text { Vergari et al., 2017, } \\
2016\end{array}$ & $\begin{array}{l}\text { Outer annulus } \\
\text { fibrosus of } \\
\text { intervertebral } \\
\text { disc }\end{array}$ & Bovine & $\begin{array}{l}\text { Second harmonic } \\
\text { generation confocal } \\
\text { microscopy }\end{array}$ & $\begin{array}{l}\text { 2D DIC custom } \\
\text { MATLAB algorithm } \\
\text { Collagen bundle texture }\end{array}$ \\
\hline Baldit et al., 2014 & $\begin{array}{l}\text { Sections of } \\
\text { annulus fibrosus } \\
\text { of intervertebral } \\
\text { disc }\end{array}$ & Porcine & Stereo cameras & $\begin{array}{l}\text { KelKins } \\
\text { (Wattrisse et al., 2001) } \\
\text { Tissue texture }\end{array}$ \\
\hline $\begin{array}{l}\text { Kaviani et al., } 2016 \\
\text { Amini et al., } 2013\end{array}$ & $\begin{array}{l}\text { Cartilage growth } \\
\text { plates }\end{array}$ & Porcine & Confocal microscopy & $\begin{array}{l}\text { Custom MATLAB } \\
\text { algorithm } \\
\text { Tissue texture }\end{array}$ \\
\hline
\end{tabular}




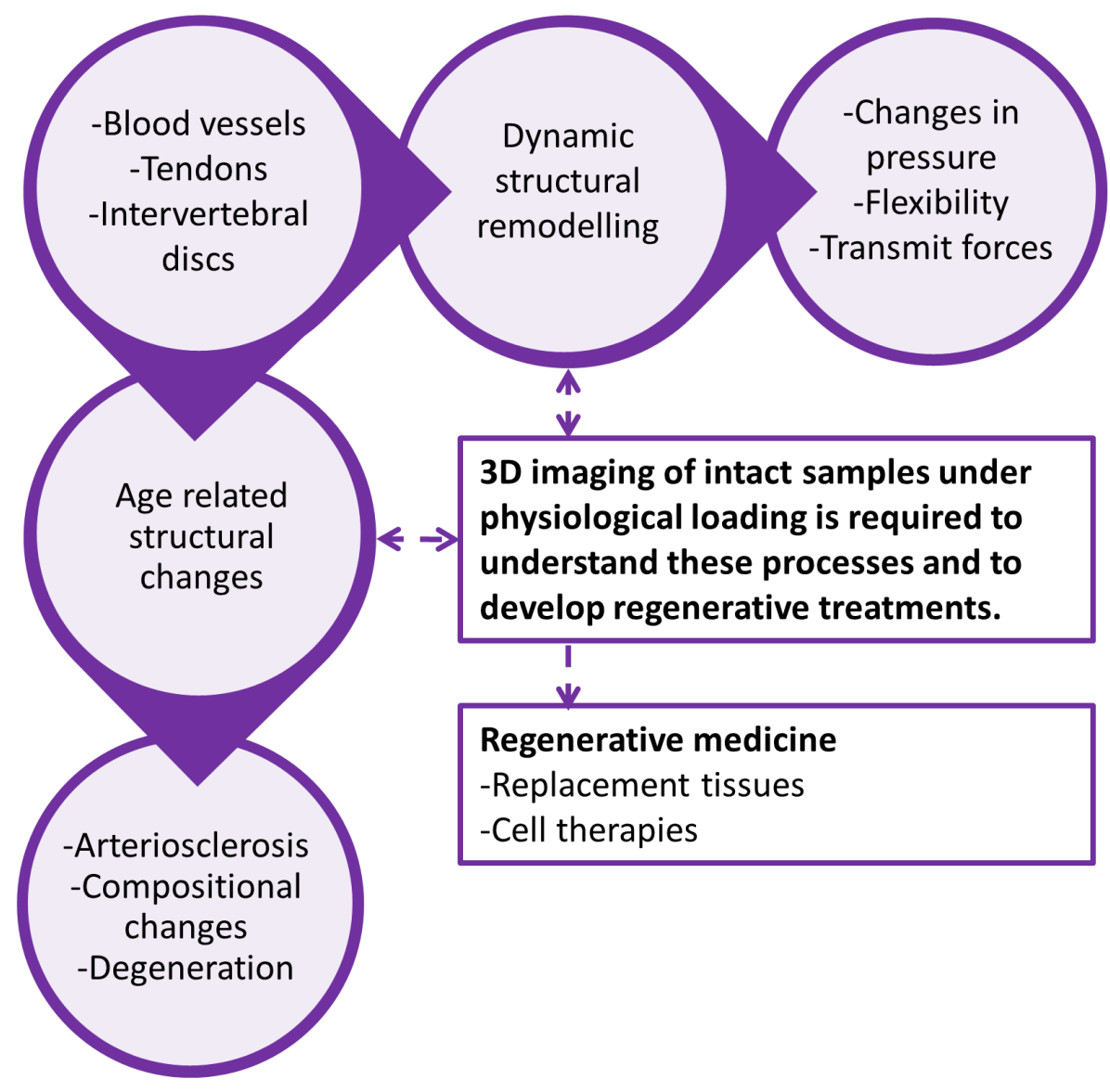

Figure 1. In situ imaging studies are essential to characterise biological tissue structure during function, ageing and to develop regenerative treatments. 
a)

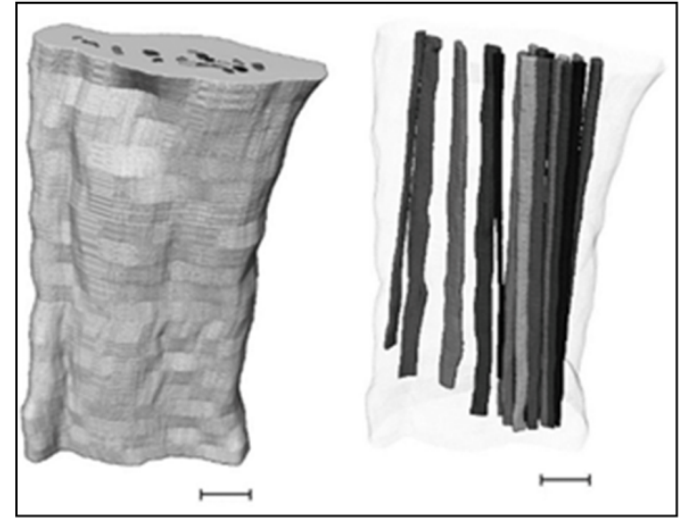

b)

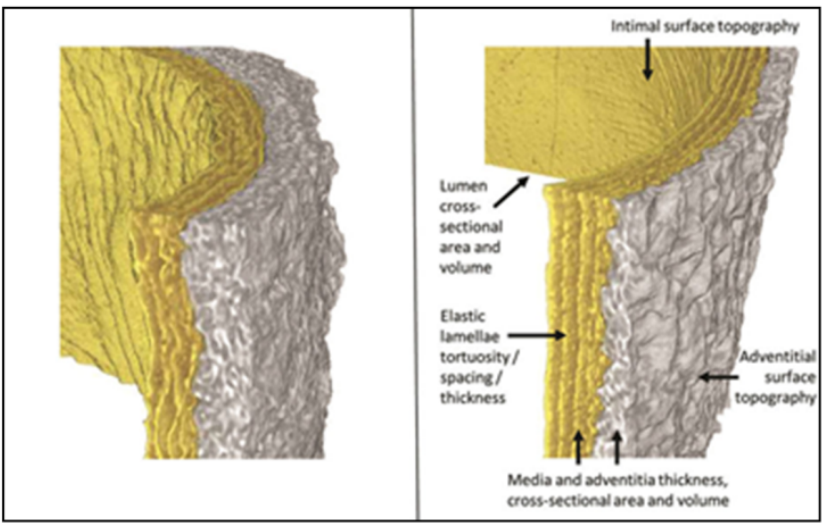

c)

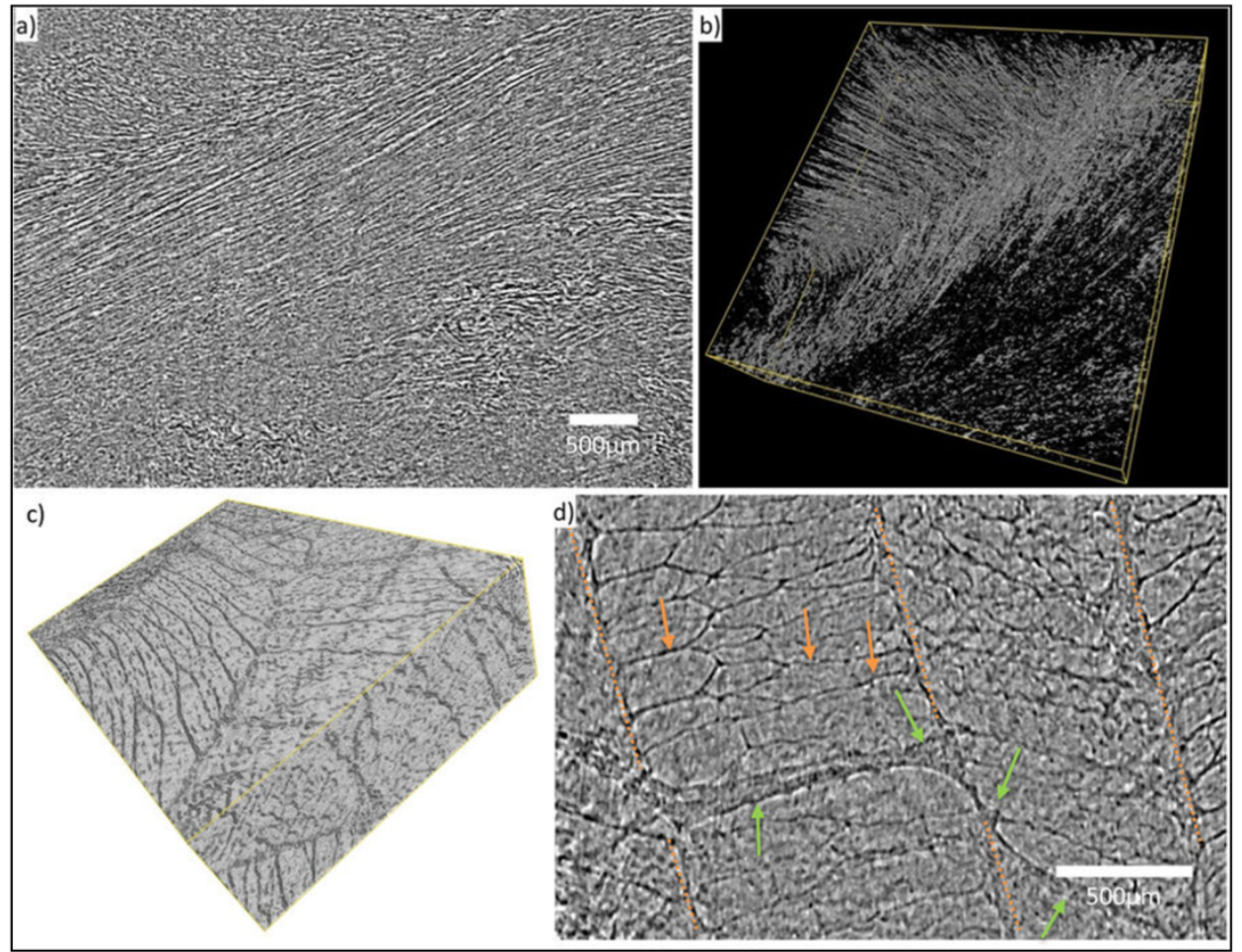

Figure 2. MicroCT imaging of soft tissue. Individual fascicles have been resolved in tendon stained with iodine potassium iodide (a) (Shearer et al., 2016). Paraffin embedded unpressurised and pressurised aorta imaged using in-line phase contrast microCT (b) (Walton et al., 2015). Native annulus fibrosus of the intervertebral disc imaged using in-line phase contrast synchrotron microCT (c) (Disney et al., 2017). All panels adapted with permission. 


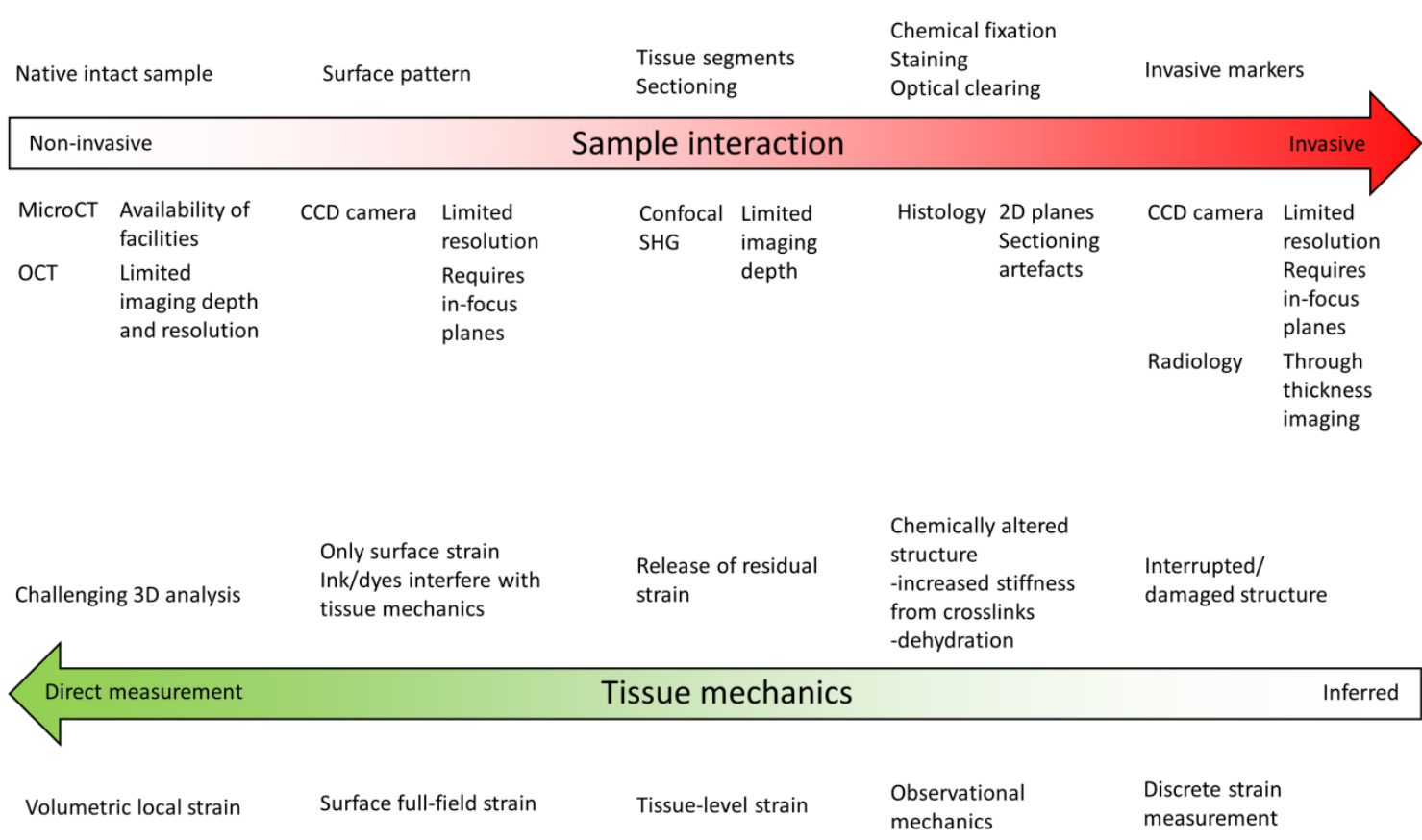

Figure 3. In situ imaging to quantify tissue mechanics. The top arrow (sample interaction) describes the sample preparation required for each different imaging technique and their limitations. Tissue mechanics ranging from volumetric strain to discrete strain and observational mechanics can be related to the above imaging techniques. 
a)

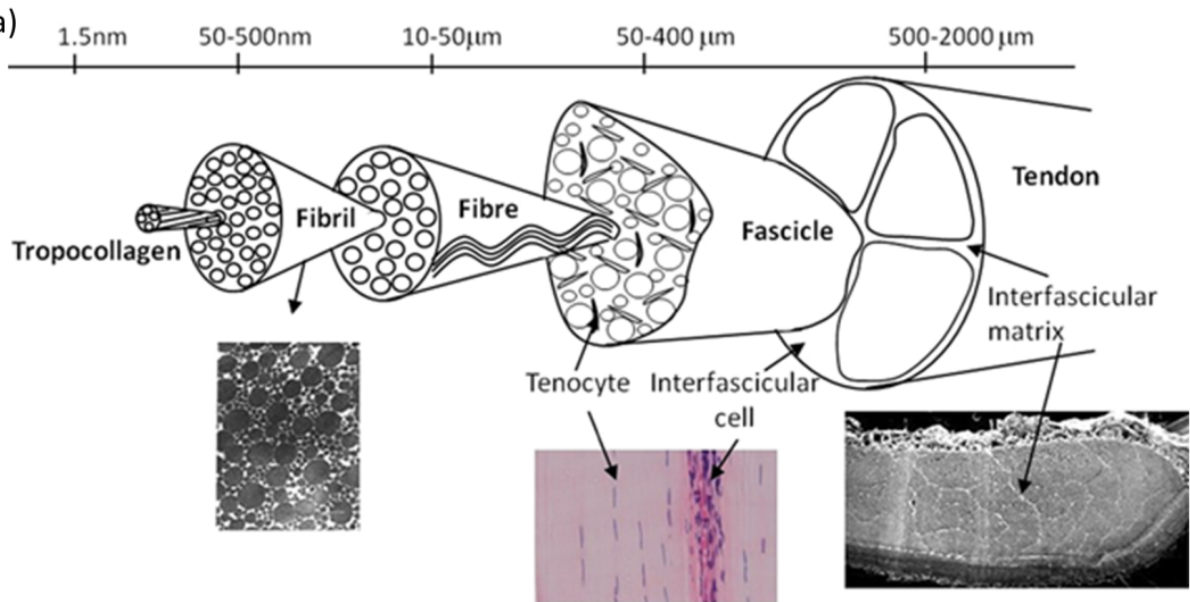

b)

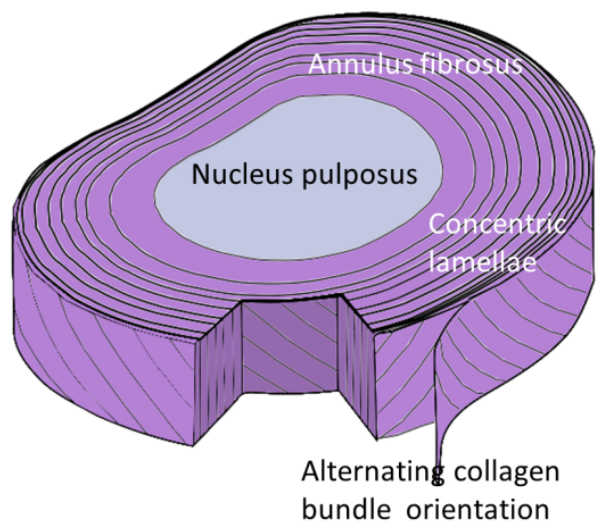

c)

helically arranged fibre reinforced adventitial layer

transversely isotropic fibrereinforced medial unit

helically arranged fibrereinforced intimal layer

collagen fibres

elastic lamina externa collagen fibril smooth muscle cell elastic fibril -

elastic lamina interna -

Figure 4. Schematics showing the microstructure of different organs. Tendon (a) (Screen et al., 2015), intervertebral disc (b) (Disney et al., 2017) and artery (c) (Gasser et al., 2006) are given as examples. All panels adapted with permission. 


\section{In situ imaging}

Sample preparation

- Dissection of intact specimen

- Customised grips or sample holders

- Hydration control

Loading regime

- Precise displacement control

- Small displacement steps to allow for subsequent image correlation

- Include relaxation time to account for viscoelastic behaviour

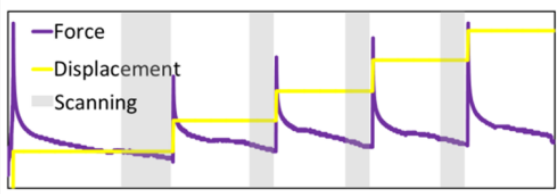

\section{MicroCT imaging}

- In-line phase contrast for native soft tissue imaging

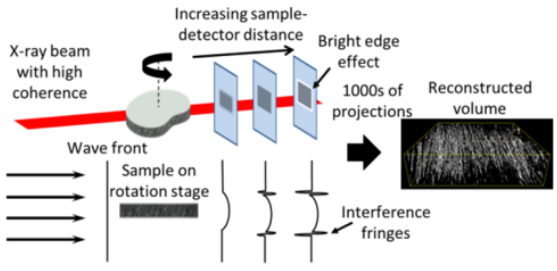

- Sufficient resolution to resolve microstructural texture

- Reconstruction algorithm

- Synchrotron microCT for high signal:noise and fast imaging

\section{Image processing}

- Filtering to smooth high frequency noise

- Segmentation of structures for DVC

\section{Approach}

- Local: Independent

sub-volumes

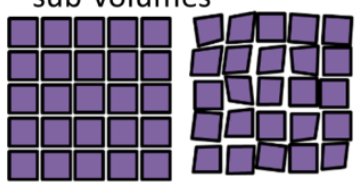

- Global: Finite elements with nodes

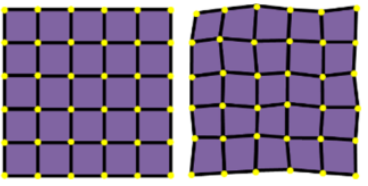

Volume of interest

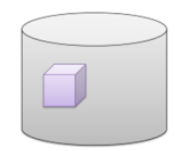

Select volume for DVC

\section{Point cloud}

- Sub-volume size

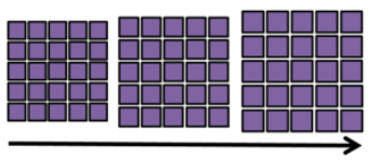

Increasing reliability Decreasing tracking resolution

- Point density or subvolume overlap

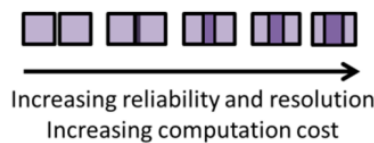

- Point distribution

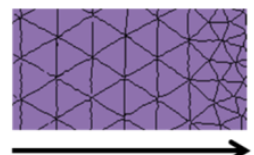

Increasing point density for regions of interest

Correlation function
Strain calculation and interpretation

\section{Filter DVC results}

- Threshold points on tracking residual

- Light filtering of displacement values

\section{Strain calculation}

- Interpolation of displacement points

- Displacement gradient calculation

$$
\begin{gathered}
\boldsymbol{D}=\left[\begin{array}{lll}
\frac{\partial u}{\partial x} & \frac{\partial u}{\partial y} & \frac{\partial u}{\partial z} \\
\frac{\partial v}{\partial x} & \frac{\partial v}{\partial y} & \frac{\partial v}{\partial z} \\
\frac{\partial w}{\partial x} & \frac{\partial w}{\partial y} & \frac{\partial w}{\partial z}
\end{array}\right) \begin{array}{l}
\text { Choose } \\
\text { suitable step } \\
\text { size }
\end{array} \\
\text { - Lagrange strain tensor } \\
\boldsymbol{L}=\frac{1}{2}\left[\boldsymbol{D}+\boldsymbol{D}^{T}+\boldsymbol{D}^{T} \boldsymbol{D}\right]
\end{gathered}
$$

Select type of strain depending on loading mode and sample

- Maximum or minimum principle strain

- Maximum shear

- Map as circumferential or hoop strain

\section{Visualise strain alongside} microstructure

- Display possible relationship between strain and microstructure

- Soft tissue deformation mechanisms

Figure 5. Proposed workflow for soft tissue microCT-DVC studies. 
References

Ackerman, J. E., Bah, I., Jonason, J. H., Buckley, M. R. \& Loiselle, A. E. (2017) Aging does not alter tendon mechanical properties during homeostasis, but does impair flexor tendon healing. Journal of Orthopaedic Research.

Adams, M., McNally, D. \& Dolan, P. (1996) 'STRESS'DISTRIBUTIONS INSIDE INTERVERTEBRAL DISCS. J Bone Joint Surg Br, 78, 965-972.

Adams, M. A. \& Dolan, P. (2012) Intervertebral disc degeneration: evidence for two distinct phenotypes. Journal of anatomy, 221, 497-506.

Adnan, K., Robinson, C., Biggs, M., Morgan, B., Rutty, G., Borsen, A., Dijkstra, J., Kitslaar, P. \& Adlam, D. (2017) P2357Measurement of coronary artery compliance and stiffness index with novel application of optical coherence tomography in re-pressurised cadaveric coronary arteries. European Heart Journal, 38.

Allen, W. M., Chin, L., Wijesinghe, P., Kirk, R. W., Latham, B., Sampson, D. D., Saunders, C. M. \& Kennedy, B. F. (2016) Wide-field optical coherence micro-elastography for intraoperative assessment of human breast cancer margins. Biomedical optics express, 7, 4139-4153.

Amini, S., Mortazavi, F., Sun, J., Levesque, M., Hoemann, C. D. \& Villemure, I. (2013) Stress relaxation of swine growth plate in semi-confined compression: depth dependent tissue deformational behavior versus extracellular matrix composition and collagen fiber organization. Biomechanics and modeling in mechanobiology, 1-12.

Appel, A. A., Anastasio, M. A., Larson, J. C. \& Brey, E. M. (2013) Imaging challenges in biomaterials and tissue engineering. Biomaterials, 34, 6615-6630.

Badel, P., Avril, S., Lessner, S. \& Sutton, M. (2012) Mechanical identification of layer-specific properties of mouse carotid arteries using 3D-DIC and a hyperelastic anisotropic constitutive model. Computer methods in biomechanics and biomedical engineering, 15, 37-48. 
Baldit, A., Ambard, D., Cherblanc, F. \& Royer, P. (2014) Experimental analysis of the transverse mechanical behaviour of annulus fibrosus tissue. Biomechanics and Modeling in Mechanobiology, 13, 643-652.

Balint, R., Lowe, T. \& Shearer, T. (2016) Optimal contrast agent staining of ligaments and tendons for X-ray computed tomography. PloS one, 11, e0153552.

Bay, B. K. (1995) Texture correlation: a method for the measurement of detailed strain distributions within trabecular bone. Journal of Orthopaedic Research, 13, 258-267.

Bay, B. K., Smith, T. S., Fyhrie, D. P. \& Saad, M. (1999) Digital volume correlation: three-dimensional strain mapping using X-ray tomography. Experimental mechanics, 39, 217-226.

Bersi, M. R., Bellini, C., Di Achille, P., Humphrey, J. D., Genovese, K. \& Avril, S. (2016) Novel methodology for characterizing regional variations in the material properties of murine aortas. Journal of biomechanical engineering, 138, 071005.

Bruehlmann, S. B., Matyas, J. R. \& Duncan, N. A. (2004) ISSLS prize winner: collagen fibril sliding governs cell mechanics in the anulus fibrosus: an in situ confocal microscopy study of bovine discs. Spine, 29, 2612-2620.

Cassidy, J., Hiltner, A. \& Baer, E. (1989) Hierarchical structure of the intervertebral disc. Connective tissue research, 23, 75-88.

Cavinato, C., Helfenstein-Didier, C., Olivier, T., Du Roscoat, S. R., Laroche, N. \& Badel, P. (2017) Biaxial loading of arterial tissues with 3D in situ observations of adventitia fibrous microstructure: A method coupling multi-photon confocal microscopy and bulge inflation test. Journal of the Mechanical Behavior of Biomedical Materials, 74, 488-498.

Couppe, C., Hansen, P., Kongsgaard, M., Kovanen, V., Suetta, C., Aagaard, P., Kjaer, M. \& Magnusson, S. P. (2009) Mechanical properties and collagen cross-linking of the patellar tendon in old and young men. Journal of Applied Physiology, 107, 880-886. 
Dall’Ara, E., Peña-Fernández, M., Palanca, M., Giorgi, M., Cristofolini, L. \& Tozzi, G. (2017) Precision of Digital Volume Correlation Approaches for Strain Analysis in Bone Imaged with MicroComputed Tomography at Different Dimensional Levels. Frontiers in Materials, 4.

Descamps, E., Sochacka, A., De Kegel, B., Van Loo, D., Van Hoorebeke, L. \& Adriaens, D. (2014) Soft tissue discrimination with contrast agents using micro-CT scanning. Belgian Journal of Zoology, 144, 20-40.

Disney, C., Madi, K., Bodey, A., Lee, P., Hoyland, J. \& Sherratt, M. (2017) Visualising the 3D microstructure of stained and native intervertebral discs using X-ray microtomography. Scientific Reports, 7.

Dobrynin, A. V. \& Carrillo, J.-M. Y. (2010) Universality in nonlinear elasticity of biological and polymeric networks and gels. Macromolecules, 44, 140-146.

Eyre, D. R. \& Muir, H. (1977) Quantitative analysis of types I and II collagens in human intervertebral discs at various ages. Biochimica et Biophysica Acta (BBA)-Protein Structure, 492, 29-42.

Fang, F. \& Lake, S. P. (2015) Multiscale strain analysis of tendon subjected to shear and compression demonstrates strain attenuation, fiber sliding, and reorganization. Journal of Orthopaedic Research, 33, 1704-1712.

Fang, F. \& Lake, S. P. (2017) Experimental evaluation of multiscale tendon mechanics. Journal of Orthopaedic Research, 35, 1353-1365.

Feldkamp, L., Davis, L. \& Kress, J. (1984) Practical cone-beam algorithm. JOSA A, 1, 612-619.

Feldkamp, L. A., Goldstein, S. A., Parfitt, M. A., Jesion, G. \& Kleerekoper, M. (1989) The direct examination of three-dimensional bone architecture in vitro by computed tomography. Journal of bone and mineral research, 4, 3-11.

Fessel, G., Li, Y., Diederich, V., Guizar-Sicairos, M., Schneider, P., Sell, D. R., Monnier, V. M. \& Snedeker, J. G. (2014) Advanced glycation end-products reduce collagen molecular sliding to affect collagen fibril damage mechanisms but not stiffness. PloS one, 9, e110948. 
Franz, J. R., Slane, L. C., Rasske, K. \& Thelen, D. G. (2015) Non-uniform in vivo deformations of the human Achilles tendon during walking. Gait \& posture, 41, 192-197.

Fu, J., Pierron, F. \& Ruiz, P. D. (2013) Elastic stiffness characterization using three-dimensional fullfield deformation obtained with optical coherence tomography and digital volume correlation. Journal of biomedical optics, 18, 121512-121512.

Gasser, T. C., Ogden, R. W. \& Holzapfel, G. A. (2006) Hyperelastic modelling of arterial layers with distributed collagen fibre orientations. Journal of the royal society interface, 3, 15-35.

Genovese, K. (2009) A video-optical system for time-resolved whole-body measurement on vascular segments. Optics and Lasers in Engineering, 47, 995-1008.

Genovese, K., Lee, Y., Lee, A. \& Humphrey, J. (2013) An improved panoramic digital image correlation method for vascular strain analysis and material characterization. Journal of the mechanical behavior of biomedical materials, 27, 132-142.

Goh, K., Holmes, D., Lu, H.-Y., Richardson, S., Kadler, K., Purslow, P. \& Wess, T. (2008) Ageing changes in the tensile properties of tendons: influence of collagen fibril volume fraction. Journal of biomechanical engineering, 130, 021011.

Graham, H. K., Akhtar, R., Kridiotis, C., Derby, B., Kundu, T., Trafford, A. W. \& Sherratt, M. J. (2011) Localised micro-mechanical stiffening in the ageing aorta. Mechanisms of ageing and development, 132, 459-467.

Guerin, H. L. \& Elliott, D. M. (2007) Ouantifying the contributions of structure to annulus fibrosus mechanical function using a nonlinear, anisotropic, hyperelastic model. Journal of Orthopaedic Research, 25, 508-516.

Gullbrand, S. E., Ashinsky, B. G., Martin, J. T., Pickup, S., Smith, L. J., Mauck, R. L. \& Smith, H. E. (2016) Correlations between quantitative $\mathrm{T} 2$ and $\mathrm{T} 1 \rho \mathrm{MRI}$, mechanical properties and biochemical composition in a rabbit lumbar intervertebral disc degeneration model. Journal of Orthopaedic Research, 34, 1382-1388. 
Gupta, H., Seto, J., Krauss, S., Boesecke, P. \& Screen, H. (2010) In situ multi-level analysis of viscoelastic deformation mechanisms in tendon collagen. Journal of structural biology, 169, $183-191$.

Han, S. K., Chen, C. W., Wierwille, J., Chen, Y. \& Hsieh, A. H. (2015) Three dimensional mesoscale analysis of translamellar cross-bridge morphologies in the annulus fibrosus using optical coherence tomography. Journal of Orthopaedic Research.

Han, W. M., Heo, S.-J., Driscoll, T. P., Delucca, J. F., McLeod, C. M., Smith, L. J., Duncan, R. L., Mauck, R. L. \& Elliott, D. M. (2016) Microstructural Heterogeneity in Native and Engineered Fibrocartilage Directs Micromechanics and Mechanobiology. Nature materials, 15, 477.

Happel, C. M., Klose, C., Witton, G., Angrisani, G. L., Wienecke, S., Groos, S., Bach, F.-W., Bormann, D., Männer, J. \& Yelbuz, T. M. (2010) Non-Destructive, High-Resolution 3-Dimensional Visualization of a Cardiac Defect in the Chick Embryo Resembling Complex Heart Defect in Humans Using Micro-Computed Tomography Double Outlet Right Ventricle With Left Juxtaposition of Atrial Appendages. Circulation, 122, e561-e564.

Hayashi, K. \& Hirayama, E. (2017) Age-related changes of wall composition and collagen cross-linking in the rat carotid artery-In relation with arterial mechanics. Journal of the mechanical behavior of biomedical materials, 65, 881-889.

Helfenstein-Didier, C., Taïnoff, D., Viville, J., Adrien, J., Maire, É. \& Badel, P. (2017) Tensile rupture of medial arterial tissue studied by X-ray micro-tomography on stained samples. Journal of the Mechanical Behavior of Biomedical Materials.

Hickey, D. S. \& Hukins, D. W. (1979) Effect of methods of preservation on the arrangement of collagen fibrils in connective tissue matrices: an x-ray diffraction study of annulus fibrosus. Connective tissue research, 6, 223-228.

Humzah, M. \& Soames, R. (1988) Human intervertebral disc: structure and function. The Anatomical Record, 220, 337-356. 
Jiang, Y., Tong, Y., Xiao, T. \& Lu, S. (2012) Phase-contrast microtomography with synchrotron radiation technology: A new noninvasive technique to analyze the three-dimensional structure of dermal tissues. Dermatology, 225, 75-80.

Kalson, N., Malone, P., Bradley, R., Withers, P. \& Lees, V. (2012) Fibre bundles in the human extensor carpi ulnaris tendon are arranged in a spiral. Journal of Hand Surgery (European Volume), 37, $550-554$.

Karakolis, T. \& Callaghan, J. P. (2015) Localized strain measurements of the intervertebral disc annulus during biaxial tensile testing. Computer methods in biomechanics and biomedical engineering, 18, 1737-1743.

Kaviani, R., Londono, I., Parent, S., Moldovan, F. \& Villemure, I. (2016) Growth plate cartilage shows different strain patterns in response to static versus dynamic mechanical modulation. Biomechanics and modeling in mechanobiology, 15, 933-946.

Kennedy, B. F., McLaughlin, R. A., Kennedy, K. M., Chin, L., Curatolo, A., Tien, A., Latham, B., Saunders, C. M. \& Sampson, D. D. (2014) Optical coherence micro-elastography: mechanicalcontrast imaging of tissue microstructure. Biomedical optics express, 5, 2113-2124.

Kennedy, B. F., McLaughlin, R. A., Kennedy, K. M., Chin, L., Wijesinghe, P., Curatolo, A., Tien, A., Ronald, M., Latham, B. \& Saunders, C. M. (2015) Investigation of optical coherence microelastography as a method to visualize cancers in human breast tissue. Cancer Research, 75, 3236-3245.

Kim, J.-H., Avril, S., Duprey, A. \& Favre, J.-P. (2012) Experimental characterization of rupture in human aortic aneurysms using a full-field measurement technique. Biomechanics and modeling in mechanobiology, 11, 841-853.

Krasny, W., Morin, C., Magoariec, H. \& Avril, S. (2017) A comprehensive study of layer-specific morphological changes in the microstructure of carotid arteries under uniaxial load. Acta Biomaterialia. 
Lake, S. P., Miller, K. S., Elliott, D. M. \& Soslowsky, L. J. (2009) Effect of fiber distribution and realignment on the nonlinear and inhomogeneous mechanical properties of human supraspinatus tendon under longitudinal tensile loading. Journal of Orthopaedic Research, 27, 1596-1602.

Lamouche, G., Kennedy, B. F., Kennedy, K. M., Bisaillon, C.-E., Curatolo, A., Campbell, G., Pazos, V. \& Sampson, D. D. (2012) Review of tissue simulating phantoms with controllable optical, mechanical and structural properties for use in optical coherence tomography. Biomedical optics express, 3, 1381-1398.

Larin, K. V. \& Sampson, D. D. (2017) Optical coherence elastography-OCT at work in tissue biomechanics. Biomedical optics express, 8, 1172-1202.

LePage, W. S., Daly, S. H. \& Shaw, J. A. (2016) Cross polarization for improved digital image correlation. Experimental Mechanics, 56, 969-985.

Lionello, G., Sirieix, C. \& Baleani, M. (2014) An effective procedure to create a speckle pattern on biological soft tissue for digital image correlation measurements. Journal of the mechanical behavior of biomedical materials, 39, 1-8.

Locke, R. C., Peloquin, J. M., Lemmon, E. A., Szostek, A., Elliott, D. M. \& Killian, M. L. (2017) Strain Distribution of Intact Rat Rotator Cuff Tendon-to-Bone Attachments and Attachments With Defects. Journal of Biomechanical Engineering, 139, 111007.

Madi, K., Tozzi, G., Zhang, Q., Tong, J., Cossey, A., Au, A., Hollis, D. \& Hild, F. (2013) Computation of full-field displacements in a scaffold implant using digital volume correlation and finite element analysis. Medical engineering \& physics, 35, 1298-1312.

Mallett, K. F. \& Arruda, E. M. (2017) Digital image correlation-aided mechanical characterization of the anteromedial and posterolateral bundles of the anterior cruciate ligament. Acta Biomaterialia.

Marchand, F. \& Ahmed, A. M. (1990) Investigation of the laminate structure of lumbar disc anulus fibrosus. Spine, 15, 402-410. 
Martin, C., Sun, W., Primiano, C., McKay, R. \& Elefteriades, J. (2013) Age-dependent ascending aorta mechanics assessed through multiphase CT. Annals of biomedical engineering, 41, 25652574.

Metscher, B. D. (2009a) MicroCT for comparative morphology: simple staining methods allow highcontrast 3D imaging of diverse non-mineralized animal tissues. BMC physiology, 9, 11.

Metscher, B. D. (2009b) MicroCT for developmental biology: A versatile tool for high-contrast 3D imaging at histological resolutions. Developmental Dynamics, 238, 632-640.

Michalek, A. J., Buckley, M. R., Bonassar, L. J., Cohen, I. \& latridis, J. C. (2009) Measurement of local strains in intervertebral disc anulus fibrosus tissue under dynamic shear: Contributions of matrix fiber orientation and elastin content. Journal of Biomechanics, 42, 2279-2285.

Michalek, A. J., Gardner-Morse, M. G. \& latridis, J. C. (2012) Large residual strains are present in the intervertebral disc annulus fibrosus in the unloaded state. Journal of Biomechanics, 45, $1227-1231$

Mizutani, R. \& Suzuki, Y. (2012) X-ray microtomography in biology. Micron, 43, 104-115.

Nahas, A., Bauer, M., Roux, S. \& Boccara, A. C. (2013) 3D static elastography at the micrometer scale using Full Field OCT. Biomedical optics express, 4, 2138-2149.

Naveh, G. R. S., Brumfeld, V., Dean, M., Shahar, R. \& Weiner, S. (2014) Direct MicroCT imaging of non-mineralized connective tissues at high resolution. Connective Tissue Research, 55, 5260.

Neidlinger-Wilke, C., Galbusera, F., Pratsinis, H., Mavrogonatou, E., Mietsch, A., Kletsas, D. \& Wilke, H.-J. (2014) Mechanical loading of the intervertebral disc: from the macroscopic to the cellular level. European Spine Journal, 23, 333-343.

Newell, N., Little, J., Christou, A., Adams, M., Adam, C. \& Masouros, S. (2017) Biomechanics of the human intervertebral disc: a review of testing techniques and results. Journal of the mechanical behavior of biomedical materials. 
Nieminen, H. J., Ylitalo, T., Karhula, S., Suuronen, J.-P., Kauppinen, S., Serimaa, R., Hæggström, E., Pritzker, K. P., Valkealahti, M. \& Lehenkari, P. (2015) Determining Collagen Distribution in Articular Cartilage Using Contrast-Enhanced Micro-Computed Tomography. Osteoarthritis and Cartilage.

Nierenberger, M., Rémond, Y., Ahzi, S. \& Choquet, P. (2015) Assessing the three-dimensional collagen network in soft tissues using contrast agents and high resolution micro-CT: application to porcine iliac veins. Comptes Rendus Biologies.

Ning, J., Xu, S., Wang, Y., Lessner, S. M., Sutton, M. A., Anderson, K. \& Bischoff, J. E. (2010) Deformation measurements and material property estimation of mouse carotid artery using a microstructure-based constitutive model. Journal of biomechanical engineering, 132, 121010.

O'Connell, M. K., Murthy, S., Phan, S., Xu, C., Buchanan, J., Spilker, R., Dalman, R. L., Zarins, C. K., Denk, W. \& Taylor, C. A. (2008) The three-dimensional micro-and nanostructure of the aortic medial lamellar unit measured using 3D confocal and electron microscopy imaging. Matrix Biology, 27, 171-181.

Palanca, M., Bodey, A. J., Giorgi, M., Viceconti, M., Lacroix, D., Cristofolini, L. \& Dall'Ara, E. (2017) Local displacement and strain uncertainties in different bone types by digital volume correlation of synchrotron microtomograms. Journal of Biomechanics.

Panjabi, M. M., Oxland, T., Yamamoto, I. \& Crisco, J. (1994) Mechanical behavior of the human lumbar and lumbosacral spine as shown by three-dimensional load-displacement curves. JBJS, 76, 413-424.

Pauwels, E., Van Loo, D., Cornillie, P., Brabant, L. \& Van Hoorebeke, L. (2013) An exploratory study of contrast agents for soft tissue visualization by means of high resolution X-ray computed tomography imaging. Journal of microscopy, 250, 21-31.

Pedersen, J. A. \& Swartz, M. A. (2005) Mechanobiology in the third dimension. Annals of biomedical engineering, 33, 1469-1490. 
Raj, P. P. (2008) Intervertebral Disc: Anatomy-Physiology-Pathophysiology-Treatment. Pain Practice, $8,18-44$.

Richardson, D. S. \& Lichtman, J. W. (2015) Clarifying tissue clearing. Cell, 162, 246-257.

Richardson, S. M., Freemont, A. J. \& Hoyland, J. A. (2014) Pathogenesis of Intervertebral Disc Degeneration. In: The Intervertebral Disc. Springer.

Roux, S., Hild, F., Viot, P. \& Bernard, D. (2008) Three-dimensional image correlation from X-ray computed tomography of solid foam. Composites Part A: Applied science and manufacturing, 39, 1253-1265.

Salomon, J. A., Wang, H., Freeman, M. K., Vos, T., Flaxman, A. D., Lopez, A. D. \& Murray, C. J. (2013) Healthy life expectancy for 187 countries, 1990-2010: a systematic analysis for the Global Burden Disease Study 2010. The Lancet, 380, 2144-2162.

Schmitt, J. M. (1998) OCT elastography: imaging microscopic deformation and strain of tissue. Optics express, 3, 199-211.

Schrauwen, J., Vilanova, A., Rezakhaniha, R., Stergiopulos, N., Van De Vosse, F. \& Bovendeerd, P. (2012) A method for the quantification of the pressure dependent 3D collagen configuration in the arterial adventitia. Journal of structural biology, 180, 335-342.

Screen, H., Lee, D., Bader, D. \& Shelton, J. (2004) An investigation into the effects of the hierarchical structure of tendon fascicles on micromechanical properties. Proceedings of the Institution of Mechanical Engineers, Part H: Journal of Engineering in Medicine, 218, 109-119.

Screen, H. R., Berk, D. E., Kadler, K. E., Ramirez, F. \& Young, M. F. (2015) Tendon functional extracellular matrix. Journal of Orthopaedic Research, 33, 793-799.

Setton, L. A. \& Chen, J. (2006) Mechanobiology of the intervertebral disc and relevance to disc degeneration. JBJS, 88, 52-57.

Shearer, T., Bradley, R. S., Hidalgo-Bastida, L. A., Sherratt, M. J. \& Cartmell, S. H. (2016) Threedimensional visualisation of soft biological structures by X-ray computed micro-tomography. J Cell Sci, 129, 2483-2492. 
Sherratt, M. J. (2013) Structural proteins and arterial ageing. Artery Research, 7, 15-21.

Snigirev, A., Snigireva, I., Kohn, V., Kuznetsov, S. \& Schelokov, I. (1995) On the possibilities of x-ray phase contrast microimaging by coherent high-energy synchrotron radiation. Review of scientific instruments, 66, 5486-5492.

Storm, C., Pastore, J. J., MacKintosh, F. C., Lubensky, T. C. \& Janmey, P. A. (2005) Nonlinear elasticity in biological gels. Nature, 435, 191.

Sutton, M., Ke, X., Lessner, S., Goldbach, M., Yost, M., Zhao, F. \& Schreier, H. (2008) Strain field measurements on mouse carotid arteries using microscopic three-dimensional digital image correlation. Journal of Biomedical Materials Research Part A, 84, 178-190.

Sutton, M., Mingqi, C., Peters, W., Chao, Y. \& McNeill, S. (1986) Application of an optimized digital correlation method to planar deformation analysis. Image and Vision Computing, 4, 143-150.

Sutton, M., Wolters, W., Peters, W., Ranson, W. \& McNeill, S. (1983) Determination of displacements using an improved digital correlation method. Image and vision computing, 1, 133-139.

Szczesny, S. E., Edelstein, R. S. \& Elliott, D. M. (2014) DTAF dye concentrations commonly used to measure microscale deformations in biological tissues alter tissue mechanics.

Szczesny, S. E. \& Elliott, D. M. (2014) Interfibrillar shear stress is the loading mechanism of collagen fibrils in tendon. Acta biomaterialia, 10, 2582-2590.

Taylor, J., Scott, J., Cribb, A. \& Bosworth, T. (1992) Human intervertebral disc acid glycosaminoglycans. Journal of anatomy, 180, 137.

Thomopoulos, S., Williams, G. R., Gimbel, J. A., Favata, M. \& Soslowsky, L. J. (2003) Variation of biomechanical, structural, and compositional properties along the tendon to bone insertion site. Journal of orthopaedic research, 21, 413-419.

Thorpe, C. T., Godinho, M. S., Riley, G. P., Birch, H. L., Clegg, P. D. \& Screen, H. R. (2015) The interfascicular matrix enables fascicle sliding and recovery in tendon, and behaves more elastically in energy storing tendons. Journal of the mechanical behavior of biomedical materials, 52, 85-94. 
Tilley, J., Carr, A. \& Czernuszka, J. (2011) Atomic Force Microscopy of bulk tendon samples: affect of location and fixation on tissue ultrastructure. Micron, 42, 531-535.

United Nations, R. (2013) World Population Ageing 2013. New York.

Urban, J. P. \& Roberts, S. (2003) Degeneration of the intervertebral disc. Arthritis Res Ther, 5, 120.

Vergari, C., Chan, D., Clarke, A., Mansfield, J. C., Meakin, J. R. \& Winlove, P. C. (2017) Bovine and degenerated human annulus fibrosus: a microstructural and micromechanical comparison. Biomechanics and modeling in mechanobiology, 1-10.

Vergari, C., Mansfield, J., Meakin, J. R. \& Winlove, P. C. (2016) Lamellar and fibre bundle mechanics of the annulus fibrosus in bovine intervertebral disc. Acta biomaterialia, 37, 14-20.

Vickerton, P., Jarvis, J. \& Jeffery, N. (2013) Concentration-dependent specimen shrinkage in iodineenhanced microCT. Journal of anatomy, 223, 185-193.

Wagenseil, J. E. \& Mecham, R. P. (2009) Vascular Extracellular Matrix and Arterial Mechanics. Physiological Reviews, 89, 957-989.

Walton, L. A., Bradley, R. S., Withers, P. J., Newton, V. L., Watson, R. E., Austin, C. \& Sherratt, M. J. (2015) Morphological Characterisation of Unstained and Intact Tissue Micro-architecture by X-ray Computed Micro-and Nano-Tomography. Scientific reports, 5.

Wan, W., Yanagisawa, H. \& Gleason, R. L. (2010) Biomechanical and microstructural properties of common carotid arteries from fibulin-5 null mice. Annals of biomedical engineering, $\mathbf{3 8 ,}$ 3605-3617.

Wang, R., Brewster, L. P. \& Gleason, R. L. (2013) In-situ characterization of the uncrimping process of arterial collagen fibers using two-photon confocal microscopy and digital image correlation. Journal of biomechanics, 46, 2726-2729.

Wang, S., Rui, Y., Lu, J. \& Wang, C. (2014) Cell and molecular biology of intervertebral disc degeneration: current understanding and implications for potential therapeutic strategies. Cell proliferation, 47, 381-390. 
Wang, Y., Battié, M. C. \& Videman, T. (2012) A morphological study of lumbar vertebral endplates: radiographic, visual and digital measurements. European Spine Journal, 21, 2316-2323.

Wijesinghe, P., Johansen, N. J., Curatolo, A., Sampson, D. D., Ganss, R. \& Kennedy, B. F. (2017) Ultrahigh-resolution optical coherence elastography images cellular-scale stiffness of mouse aorta. Biophysical Journal, 113, 2540-2551.

Wilkins, S., Gureyev, T. E., Gao, D., Pogany, A. \& Stevenson, A. (1996) Phase-contrast imaging using polychromatic hard X-rays. Nature, $\mathbf{3 8 4}, 335$.

Wolinsky, H. \& Glagov, S. (1964) Structural basis for the static mechanical properties of the aortic media. Circulation research, 14, 400-413.

Yoder, J. H., Peloquin, J. M., Song, G., Tustison, N. J., Moon, S. M., Wright, A. C., Vresilovic, E. J., Gee, J. C. \& Elliott, D. M. (2014) Internal Three-Dimensional Strains in Human Intervertebral Discs Under Axial Compression Quantified Noninvasively by Magnetic Resonance Imaging and Image Registration. Journal of Biomechanical Engineering-Transactions of the Asme, 136.

Zysk, A. M., Garson, A. B., Xu, Q., Brey, E. M., Zhou, W., Brankov, J. G., Wernick, M. N., Kuszak, J. R. \& Anastasio, M. A. (2012) Nondestructive volumetric imaging of tissue microstructure with benchtop x-ray phase-contrast tomography and critical point drying. Biomedical optics express, 3, 1924-1932. 